\title{
GRAISENS MINERALIZADOS A ESTANHO E TUNGSTÊNIO NO ESTADO DO PARANÁ
}

\author{
OSWALDO FRITZSONS JÚNIOR*
}

\begin{abstract}
TIN AND TUNGSTEN-MINERALIZED GREISEN FROM PARANA STATE. For the first time greisen bodies and rocks altered by process of greisenization are defined in the Parana State. These mineralizations are in an extragranitic position and are believed to rest upon a granitic diapir. The process of greisenization has developed in metamorphic rocks as well as in albite-granite apophysis. As viewed in a regional scale it is possible to see a relationship between mineralized regions and large transcurrent faults, which is evidence of a tectonic control for these mineralizations.
\end{abstract}

INTRODUÇÃO Os trabalhos de prospecção mineral realizados em região localizada a cerca de $60 \mathrm{~km}$ a nordeste de Curitiba conduziram à descoberta de graisens** com mineralizações de Sn e W, localmente também com Nb, Ta, Bi e Mo.

Neste relato serão apresentados os resultados até agora obtidos, com enfoque nos aspectos geologicos de interesse ao assunto. $\mathrm{Na}$ área prosseguem as atividades de pesquisa mineral, que poderão num futuro próximo alicerçar melhor os dados e as interpretaçöes agora apresentados.

A localização da área é apresentada na figura 1. No texto a seguir, serão relatados, inicialmente, os dados e as conclusões referentes aos aspectos geologicos regionais e locais. Posteriormente, há um capítulo especialmente voltado aos graisens reconhecidos.

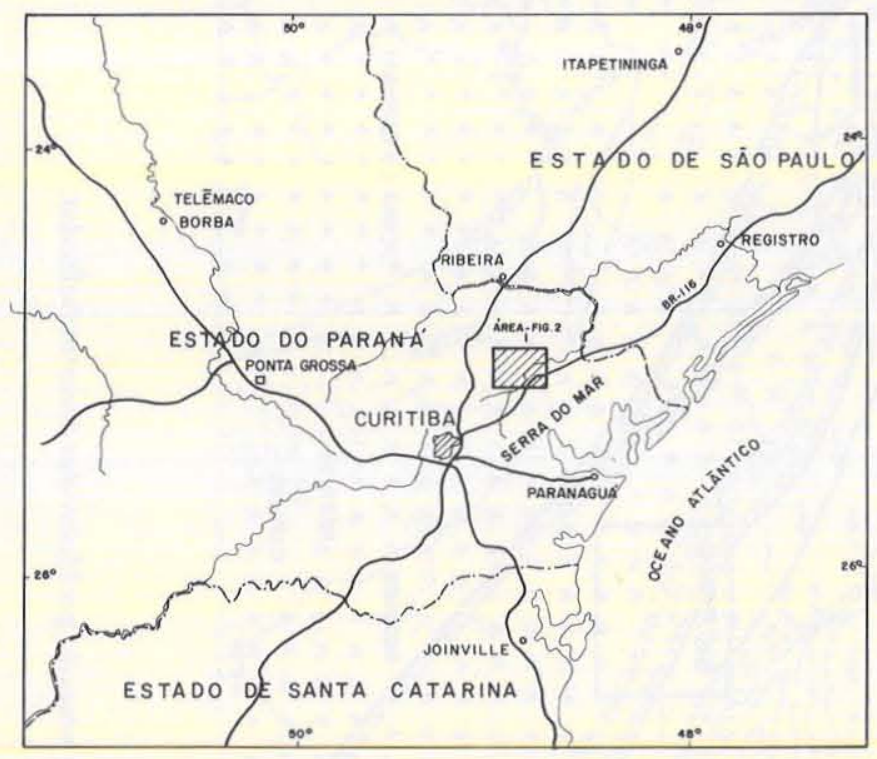

GEOLOGIA REGIONAL O esboço geologico apresentado na figura 2 é produto de uma reinterpretação e atualização dos mapas elaborados por Falcade (1982) e Fritzsons Jr. et al. (1985). Na área afloram porçöes de praticamente todas as unidades pré-cambrianas que ocorrem no Estado do Paraná. Para suas denominações foram adotadas as definições de Bigarella et al. (1967), de Fuck et al. (1971) e, também, as de Fritzson Jr. et al. (1982).

As unidades litoestratigráficas aflorantes na área são, das mais antigas para mais jovens: Complexo Cristalino, Complexo Pré-Setuva, Grupo Setuva, Grupo Açungui, "Granitóide Serrinha", rochas cataclásticas relacionadas a "Falha de Putunã" e Granito Graciosa.

O Complexo Cristalino é constituído por hornblendagranitos gnáissicos grossos, eqüigranulares, com restitos ovalados de anfibolitos, de dimensões variando de centímetros a centenas de metros. Estruturalmente são migmatitos homogeneizados, tipicamente nebulíticos com textura granular, sem foliação cataclástica.

O Complexo Pré-Setuva é provavelmente uma unidade de rochas supracrustais em relação ao Complexo Cristalino. Aflora no núcleo de um antiforme na porção central da área e também na porção sudeste, onde parece constituir uma delgada cobertura sobre as rochas do Complexo Cristalino. Trata-se de uma unidade caracterizada por uma heterogeneidade composicional acentuada de seus tipos litológicos. Também ê caracterizado por um grau metamorfico elevado e forte cataclase textural, com fenômenos localizados de anatexia. $\mathrm{Na}$ porção central da área predominam biotita-augen gnaisses e gnaisses graníticos com gradações para micaxistos e anfibolitos. A sudeste predominam tipos calciossilicáticos, biotita gnaisses, anfibolitos e mais raramente muscovita-biotita xistos, quartzitos e mármores. Fazendo uso de uma nomenclatura mais direcionada de deformação das rochas, pode-se dizer que

Figura 1 - Mapa de localização

\footnotetext{
* Gerência de Operaçōes, Minerais do Paraná S.A. (Mineropar). CEP 80030, Curitiba, PR, Brasil

** N.E.: O termo "graisens" adotado no presente trabalho é uma forma de se aportuguesar o termo de origem alemã "greisen", cuja desinência "en" corresponde à grafia no plural. Assim sendo, seria inadequado escrever "greisens". Tal forma aportuguesada já tem sido adotada por alguns outros autores.
} 

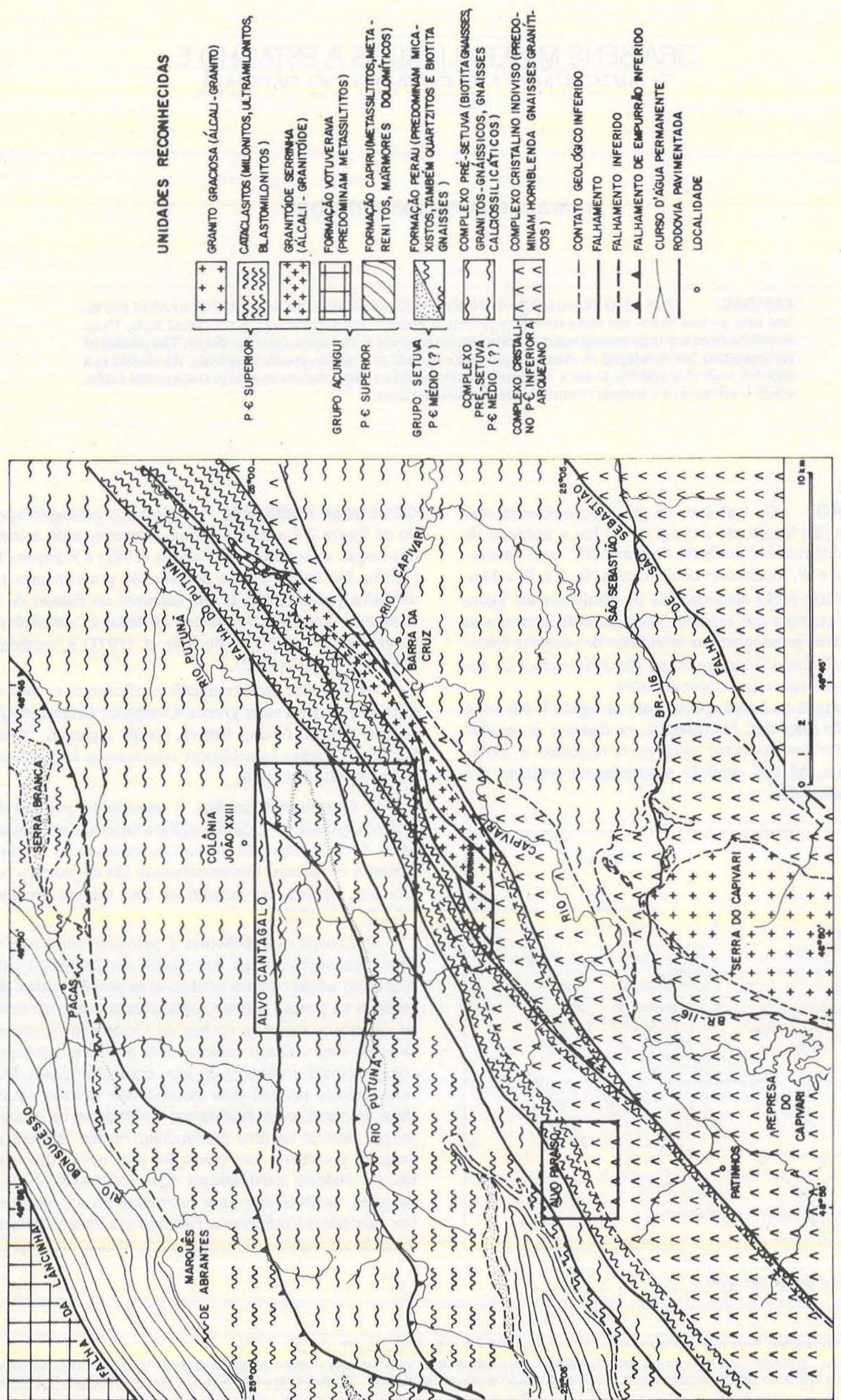
a unidade é composta por blastomilonitos e milonito-gnaisses. Tal cataclase é generalizada e seria originada por forte cisalhamento dúctil.

O Grupo Setuva acha-se representado por faixas situadas a norte da "Falha do Putunã", em ambos os flancos do antiforme que contém rochas do Complexo Pré-Setuva em seu núcleo. São característicos dessa unidade micaxistos e quartzitos fortemente afetados por transposição tectônica, intensamente dobrados. Os micaxistos são predominantemente biotitasericita xistos cinzentos, por vezes com carbonatos ou com muitas segregações concordantes de quartzo. Em um setor detalhado foram descritas passagens gradacionais desses micaxistos para tipos feldspáticos e até biotita gnaisses. Inseridos nas faixas, ocorrem pacotes lenticulares de quartzitos finos, vítreos, placoidais; a exemplo do que ocorre nas serras Branca e Bocaina. Segundo proposições de Fritzsons Jr. et al. (1982), na área ocorrem rochas tidas como basais do Grupo Setuva, classificadas como pertencentes à Formação Perau.

O Grupo Açungui acha-se representado pelas formações Capiru e Votuverava. A Formação Capiru é composta por dolomitos brancos, metassiltitos, meta-argilitos por vézes carbonosos e metarenitos que se interestratificam em bancos decamétricos. A Formação Votuverava, que ocorre no extremo NW da área, é composta por metarritmitos de natureza argilosiltosa, nos quais se intercalam bandas claras e bandas escuras carbonosas.

Dentro da zona de cisalhamento da "Falha do Putunã" aflora um corpo de rochas ígneas intrusivas, denominado neste trabalho "Granit6ide Serrinha". Trata-se de um corpo alongado na direção NE-SW, cortado por falhas com faixas de milinitização associadas. É composto por hornblenda-granitos cataclasados, granulares, de granulação média, de aspecto "sal-e-pimenta", com pequenos fenocristais de F-K ou plagioclásio imersos em matriz granítica cataclasada. Os plagioclásios mostram tendência para tipos mais sódicos e a hornblenda para ferro-hastingsita. Acredita-se que o corpo se tenha alojado na regiâo da "Falha do Putunâ" e sofrido esforços tectônicos posteriores.

As rochas cataclásticas relacionáveis à "Falha do Putunã", por sua área de ocorrência, constituem uma importante unidade litologica. É uma faixa direcionada NE-SW, com forma irregular, com espessamentos e ramificações configuradas por um feixe de fraturas semiparalelas. São, no geral, blastomilonitos, milonitos e ultramilonitos com grau de deformação diminuindo progressivamente para fora da faixa até correrem rochas regionais intactas. Predominam deformações do tipo dúctil, denotando que as rochas hoje expostas foram milonitizadas a grande profundidade. A largura variável de 2 a $4 \mathrm{~km}$ da faixa e as ramificações sigmoidais de falhamentos secundários atestam o caráter transcorrente e multifásico da "Falha do Putunâ".

$\mathrm{Na}$ porção centro-sul da área, aflora a extremidade setentrional do Granito Graciosa. Nesse setor foram descritos duas fácies: uma cinza-clara dominante e outra róseo-avermelhada. A fácies cinza-claro é constituída por granitos ineqüigranulares, de granulaçảo grossa, compostos por feldspato potássico, plagioclásio, quartzo, biotita, hornblenda e titanita. A fácies róseo-avermelhada é aparentemente mais jovem, ocorrendo em corpos tabulares; são granitos de granulação grossa, com fenocristais arredondados de quartzo imersos em massa de feldspatos grossos; são pobres em minerais máficos, tendo sido identificados biotita e hornblenda. dos de minerais pesados, oriundos de sedimentos de drenagens, levaram à definição de áreas onde ocorrem notáveis concentrações de $\mathrm{Sn}$ ou de uma superposição de $\mathrm{Sn}, \mathrm{W}, \mathrm{Nb}$ e F. Uma ilutração do fato é o mapa de isoteores de $\mathrm{Sn}$ em intervalos logarítmicos, conforme apresenta a figura 3.

Em funçåo desses resultados, resolveu-se iniciar trabalhos de prospecção mineral detalhada em dois alvos, demarcados nas figuras 2 e 3 . A seguir, serão discutidos os aspectos geologicos particulares de cada alvo.

Alvo "Paraíso" O esboço geologico desse alvo acha-se representado na figura 4. O alvo foi definido pela ocorrência de teores anômalos de Sn, em concentrados de bateia, com dois resultados maiores que 5.000 ppm (Fig. 3).

$\mathrm{Na}$ região ocorre um importante falhamento transcorrente de direção N60E, relacionado à "Falha do Putunã", com espessa faixa de rochas cataclásticas. A zona de falha separa dois blocos crustais: um a NW constituído por micaxistos do Grupo Setuva e outros a SE, com rochas do Complexo Cristalino. Entre os dois blocos, na zona de falha, ocorre uma faixa com cerca de $2 \mathrm{~km}$ de largura, composta por rochas cataclásticas.

Nas porções mais externas da faixa cataclástica predominam blastomilonitos de natureza quartzo-feldspática e, no interior da mesma, rochas mais fortemente cataclasadas, nas quais se destacam ultramilonitos, milonitos e filonitos.

Em uma porção do núcleo da zona de falha, delimitou-se uma faixa lenticular onde teria havido um hidrotermalismo generalizado. Af́ foram descritos fenômenos de epidotização, cloritização, sericitização e, localmente, turmalinização e neoformação de biotita e feldspato potássico.

Em locais específicos dessa faixa hidrotermalizada, há ocorrências de cristais disseminados de cassiterita em meio a rochas intensamente sericitizadas. Alguns concentrados de minerais pesados, obtidos a partir dessas rochas e descritos a lupa, evidenciaram cristais de cassiterita de granulometria menor que 110 mesh e, em alguns locais, foram identificados cristais de cassiterita do tipo estanho de madeira. Os teores máximos até agora obtidos foram de $0,48 \%$ de Sn por análises químicas e $150 \mathrm{~g} / \mathrm{m}^{3}$ de cassiterita, recuperáveis por bateamento de rochas alteradas. Esses dados, aliados a uma perfeita correlação entre os teores de $\mathrm{Sn}$ e os teores de $\mathrm{Cu}$, permitem inferir a existência de filões hidrotermais do tipo "cassiterita-sulfetos" de Sn (Smirnov apud Taylor 1979, p. 46).

Alvo "Cantagalo" O esboço gẹológico desse alvo acha-se representado na figura 5 . $\mathrm{O}$ alvo foi definido pela ocorrência de teores anômalos de $\mathrm{Sn}, \mathrm{W}, \mathrm{Nb}$ e Ta, detectados por prospecção geoquímica com concentrados de minerais pesados de sedimentos de drenagens. Foram obtidos teores de até $1.70 \mathrm{~g} / \mathrm{m}^{3}$ de $\mathrm{Sn}, 203 \mathrm{~g} / \mathrm{m}^{3}$ de $\mathrm{W}, 233 \mathrm{~g} / \mathrm{m}^{3}$ de Ta e 75 $\mathrm{m} / \mathrm{g}^{3}$ de $\mathrm{Nb}$. Também foram identificados inúmeros corpos de graisens, muitos dos quais mineralizados a $\mathrm{Sn}, \mathrm{W}, \mathrm{Nb}, \mathrm{Ta}, \mathrm{Bi}$ e Mo, que serão descritos adiante.

O alvo "Cantagalo" encerra basicamente três grandes unidades litologicas que fazem contatos tectônicos entre si. São, da mais antiga para a mais jovem: Complexo Pré-Setuva, Grupo Setuva e cataclasitos relacionáveis à "Falha do Putunã".

As rochas do Complexo Pré-Setuva perfazem cerca de $40 \%$ do Alvo. São agrupadas em duas assembleias: uma na porção centro-oeste da área, composta por gnaisses anatéticos e outra composta por "gnaisses heterogêneos". Esta última 


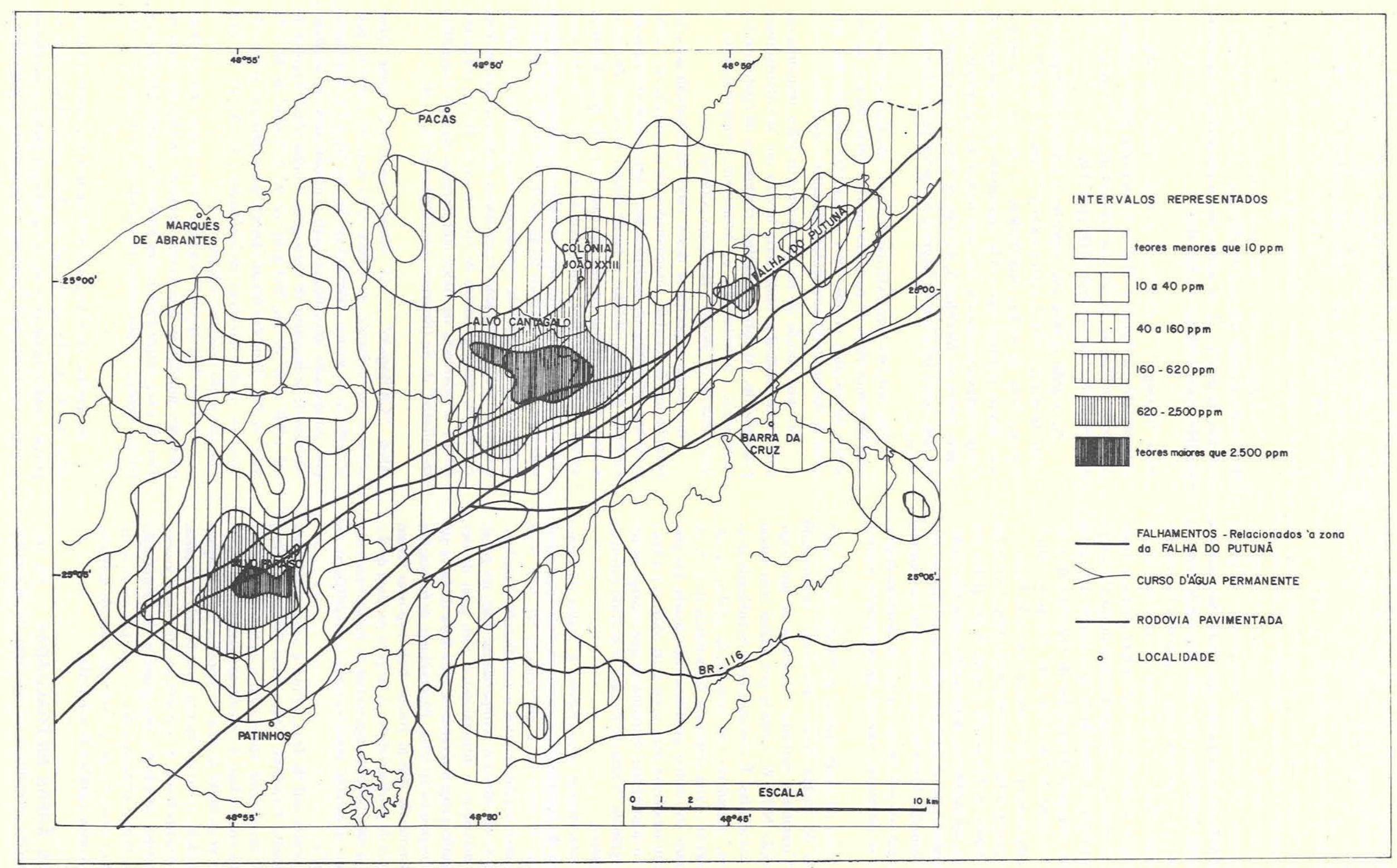

Figura 3 - Mapa de isoteores de estanho em amostras de concentrados de minerais pesados obtidos em sedimentos de drenagens 


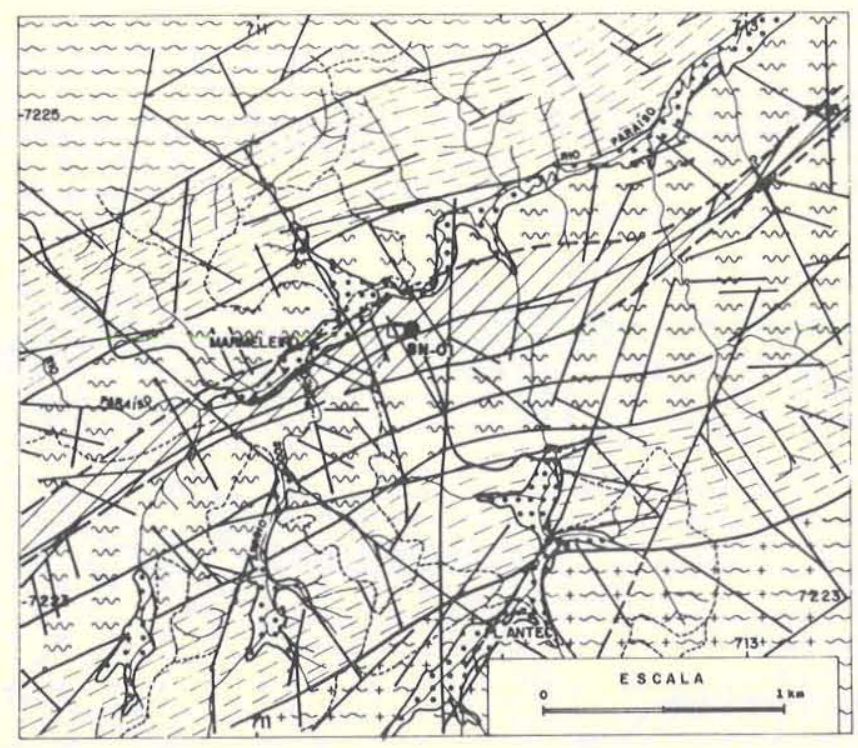

UNIDADES RECONHECIOAS

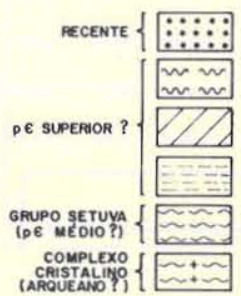

MAORES COEERTURAS ALUVIONARES

FADXA DE CATACLASE MAIS ACENTUADA ( MILONITOS, FILONITOS, ULTRAMILNITOS) FAIXA DE CATAQ ASE MAIS ACENTUADA COM HIDROTERMALISMO IEPIDOTIZA. CAOE CLORITIZACAO, ALEM DE NEOFORMACOES LOCALIZADAS DE BIOTITA E ATE FEL DSPATO POTA'SSICO

FAIXA DE CATACLASE MENOS ACENTUADA (BLASTOMILONITOS PREDOMINANTES)

\{ $\approx$ FORMAÇÃO PERAU (QUARTZO- BIOTITA XSTOS DOMINANTES)

COMPLEXo CRISTALINo ( HORNBLENDA GNAISSES gruniticos dominantes)

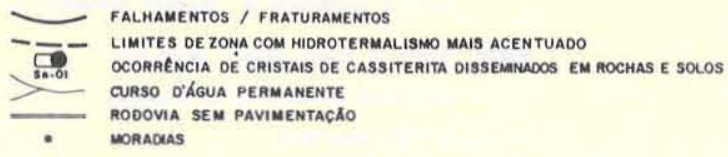

Figura 4 - Esboço geologico do Alvo "Paratso"

assembléia ocorre ao longo de duas faixas isoladas: uma no extremo norte e outra a sul. A assembléia dos gnaisses anatéticos compreende gnaisses graníticos félsicos comumente com feldspatos ocelares a lamelares em matriz cataclástica, evidenciando forte transposição tectônica. A assembléia de "gnaisses heterogêneos" compreende gnaisses bandados em escala centimétrica a decamétrica, com freqüentes intercalações ou gradações para micaxistos e anfibolitos, além de corpos pegmatóides. Um tipo também comum ê um biotita gnaisse ocelar, com porfiroclastos centimétricos de feldspato potássico.

Os contatos entre as rochas do Complexo Pré-Setuva com as do Grupo Setuva se fazem por falhamentos, em boa parte por um significativo falhamento de empurrão que teria sido verticalizado em fases deformacionais posteriores a cavalgamentos e transposições tectônicas generalizadas.

As rochas do Grupo Setuva estão em bloco tectônico localizado na porção central da área. O bloco encerra partes de um provável sinclinório, configurado pela existência de um horizonte-guia de quartzitos (Fig. 5). Os trabalhos de deta- lhamento geologico dessa unidade mostraram o quanto é perigoso estabelecer uma estratigrafia pré-cambriana baseada no grau metamórfico das unidades. Foram observadas ao longo e entre as diversas unidades balisadas pela camada-guia gradações de micaxistos de baixo grau metamórfico para gnaisses de grau médio. Alguns desses gnaisses são idênticos aos litotipos abundantes do Complexo Pré-Setuva. Desta forma, acredita-se que boa parte do que hoje é chamado de Grupo Setuva e de Complexo Pré-Setuva pertença a uma mesma unidade cronoestratigráfica. Tal unidade teria sofrido metamorfismo regional com fortes gradientes metamorficos - havendo ate núcleos anatéticos - e sofrido fortes transposiçōes tectônicas posteriores.

Foram identificadas no Grupo Setuva unidades caracterizadas pela predominância de micaxistos, de quartzitos, de leucognaisses e de biotita gnaisses ocelares.

Os micaxistos são normalmente quartzo-biotita-sericita xistos, com gradações para tipos quartzosos, para rochas calciossilicáticas, ou ainda xistos feldspáticos. Os tipos calciossilicáticos são normalmente compostos por quartzo, plagioclásio, tremolita-actinolita, epídoto, diopsídio e biotita. Alguns micaxistos, quando mais metamorfoseados, apresentam-se como estaurolita-biotita-muscovita xistos, que por vezes passam a conter feldspato potássico e plagioclásio. Na faixa mais meridional de micaxistos são caracterizadas a presença de feldspatos e uma predominância de muscovita sobre biotita. São freqüentes intercalações de espèssura métrica de leucossomas quartzo-feldspáticos, foliados concordantemente às encaixantes. São nítidas as feições de transposição tectônica com resquícios de dobras intrafoliais.

Uma unidade facilmente mapeável por fotografia aérea é a unidade quartzítica, que se compöe basicamente de bancos decamétricos de quartzitos vítreos, placoidais, puros ou localmente sericíticos, ou ainda feldspáticos. Por vezes, intercalam-se sericita-quartzo xistos ou ainda rochas calciossilicáticas.

A unidade de leucognaisses (Fig. 5) acha-se composta por augengnaisses graníticos leucocráticos, sem bandeamento nítido. São rochas basicamente compostas por microclínico, plagioclásio e quartzo, com pouca biotita. Em outros setores, essa unidade passa a ser contituída de micaxistos feldspáticos, com delgados níveis de quartzitos.

A unidade mais meridional do bloco constiturdo por rochas do Grupo Setuva contém biotita gnaisses ocelares com micaxistos subordinados. Os biotita gnaises são rochas com porfiroclastos de $\mathrm{F}-\mathrm{K}$ de $1-4 \mathrm{~cm}$, de formas ovaladas, discoidais, ou ainda lamelares, de cor rósea, imersos em matriz escura, quartzo-feldspática-biotítica.

Por todo o bloco de rochas atribuídas ao Grupo Setuva, ocorrem intercalações de corpos pegmatóides tabulares ou irregulares, que teriam sofrido ao menos uma fase deformacional, juntamente com as rochas encaixantes.

No extremo leste da área, foi reconhecido e individualizado um corpo de rochas granitóides. São granitos gnáissicos acinzentados, de granulação grossa, ineqüigranulares, com porfiroclastos de F-K em matriz de plagioclásio, quartzo e biotita. Interpreta-se como sendo um corpo intrusivo sintectônico do Grupo Setuva, que teria sofrido efeitos dinâmicos relacionados ao metamorfismo regional.

No extremo sudeste do Alvo "Cantagalo", a SE do Rio Limeira, passam a ocorrer somente milonito-gnaisses relacionáveis à "Falha do Putunã".

As coberturas aluvionares são de pouca expressão e, em geral, são condicionadas por barreiras ao entalhamento dos elementos de drenagem. São notáveis os aluviōes relacionados 


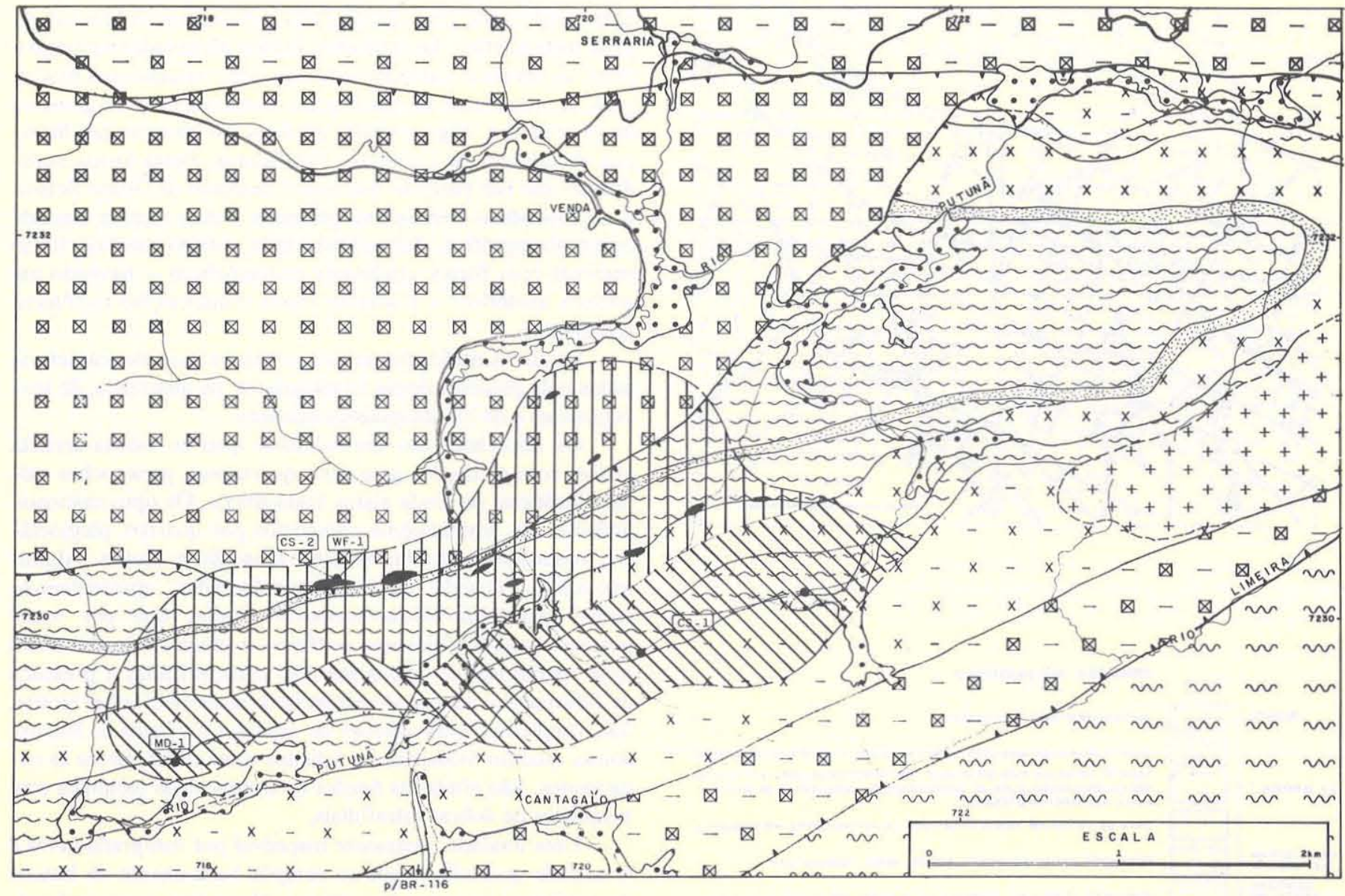

AGRUPAMENTOS LITOLÓGICOS

RECENTE $\{[\because \vdots$ MAIORES COBERTURAS ALUVIONARES

DESUPERIOR ( $)\{$ \{ W ? ROCHAS CATACLA'STICAS (BLASTOMILONITOS DE ROCHAS ORIGINAIS DE SUPERIOR ( $($ ) $\{$ h W ? QUARTZO-FELDSPÁTICAS PROVAVELMENTE DO COMPLEXO CRISTALINO) p Є MÉDIO (? ) $\left\{\left[^{+-}+\right.\right.$GRANITÚIDES (GRANITOS - GNAISSICOS COM TEXTURA PORFIROCATACL ÁS

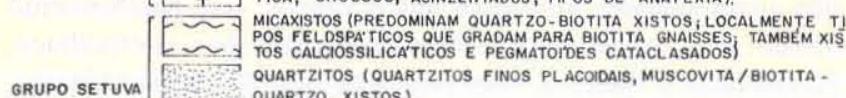
GRUPO SETUVA W OUARTIZO XISTOS)

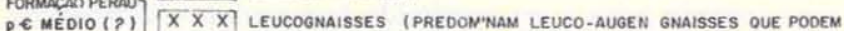
$X X X]$ GRADAR PARA QUARTZO - MICAXISTOS ?

$[X-X]$ BIOTITA - AUGEN-GNAISSES (COM MEGAPORFIROCL.ASTOS OE $K$-FELDS. - $X$ - PATO GRADAGAO PARA QUARTZO-BIOTITA XISTOS I

COMPLEXO [Q PRÉ-SETUVA $\$ \. FELLSICOS FORTEMENTE TRANSPOSTUS TECTONICAMENTE)

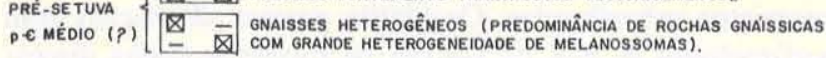
OUTRAS CONVENCÓES

A'REA DE OCORRÊNCIA DE GRAISENS DERIVADOS DAS ROCHAS ENCAL XANTES.

\section{Figura 5 - Esboço geologico do Alvo "Cantagalo"}

ao rio Putunã e algumas áreas periféricas ao Arroio Campestre. A espessura desses depósitos varia de 1 a $3 \mathrm{~m}$.

GRAISENS E ROCHAS GRAISENIZADAS No Alvo "Cartagalo", foram constatadas duas suítes de graisens. Elas diferem fundamentalmente na origem, forma de ocorrência dos conteúdos metálicos e se acham bem delimitadas geograficamente. As suítes são denominadas genericamente por "graisens derivados de albita-granitos" e "graisens derivados das rochas encaixantes".

As áreas de ocorrências de tais suítes estão ilustradas na figura 5 , na qual se pode notar também que a unidade dos leucognaisses do Grupo Setuva constitui, grosso modo, o limite entre as duas suítes.

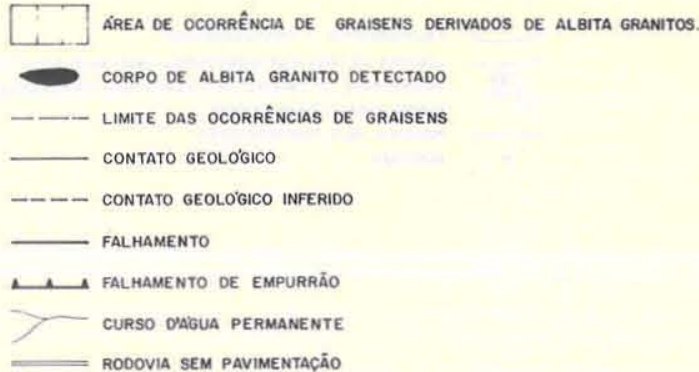

OCORRÊNCIAS MINERAIS (SOMENTE MINERALIZAÇÕES PRIMÁRIAS)

- CS-1 EXOGRAISENS CONTENDO VENULACODES DE QUARTZO E CRISTAIS GROS

- CS-2 DISSEMINAGōES DE CASSITERITA EM MICA- QuARTZO - GRAISENS DERIVA DOS DE ALBITA GRANITOS

- WfF-1] GRAISENS DERIVAdos DE aleita gRanitos com cristais de wolfra

- MD-1 DISSEMINAÇ̃ES DE MOLIBDENITA E PIRITA EM QUARTZO 
em corte da estrada que faz a ligação BR-116 - Colônia João XXIII, próxima a ponte sobre o Rio Putunã. Afora esse local, quase todas as ocorrências somente são detectáveis por blocos rolados em drenagens ou encontas. Em cerca de $60 \mathrm{~m}$ de corte de estrada que secciona os tipos litológicos locais, ocorrem quatro corpos; três dos quais tabulares, de albita-granitos com espessuras da ordem de 3 a $4 \mathrm{~m}$. Tais corpos são nitidamente intrusivos, seccionam as foliações de micaxistos encaixantes, que apresentam nos contatos auréolas termometamórficas. Internamente ou mais raramente nas bordas dos corpos, ocorrem graisens tabulares, relativamente contínuos e concordantes em relação aos contatos externos das intrusões. Os graisens nesses casos perfazem não mais de $10 \%$ da espessura dos corpos de albita-granitos. Ocorrem também algumas apofises graníticas com formas irregulares a diapíricas com dimensões variáveis, no geral, decamétricas em planta. Nesses casos, os graisens ostentam formas irregulares, havendo por ora a suspeita também de um paralelismo em relação aos contatos externos das intrusões.

Os trabalhos de prospecção geoquímica de solos apresentados por Licht (1986) deixam poucas dúvidas sobre a situaçâo espacial desses corpos. Eles se dispõem segundo linhas de fraturas de variadas direções, com predomínio daquelas direcionadas segundo E-W e, muitas vezes, em planos de falhas preexistentes. É detectada a ocorrência de núcleos com grandes concentrações metálicas, interpretados pelos dados ora disponíveis como prováveis chaminés de granitos e graisens.

Os graisens são normalmente zonados, com bordas ostentando contatos transicionais com as massas de albita-granitos, sendo difícil precisar macroscopicamente os limites da greisenização. Em quase todos os pontos onde foi possível obter medidas, sua espessura não ultrapassou $40 \mathrm{~cm}$, normalmente com 20-30 cm. Entretanto, em certos locais, foram observados blocos de mica graisen (uma das zonas) com mais de 1,5 m de diâmetros de espessura.

Uma ilustração esquemática de um corpo de "graisen derivado de albita-granito" com zonação completa é apresentada na figura 6. O granito encaixante dos graisens é maciço, de granulação fina a média, granoblástico de especo sacaroidal,

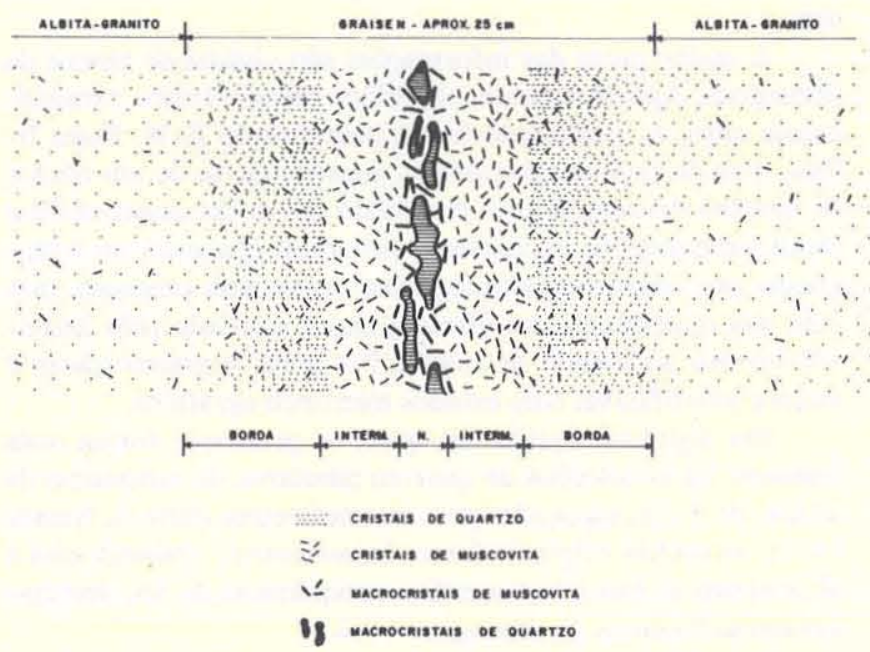

Figura 6 - Ilustração esquemática de um filão de "graisen derivado de albita-granito" com zonação perfeita eqüigranular, félsico, de cor branca. É composto por albita, quartzo, feldspato potássico e micas prateadas (muscovita e/ou zinwaldita). A albita é, por vezes, o mineral predominante desses granitos.

A zona de borda é caracterizada por rocha de granulação e aspecto semelhante ao granito, mas com aumento nos teores de quartzo e micas. São, normalmente, albita-mica-quartzo graisens sacaroidais com cristais de albita reliquiares, inclusos normalmente no quartzo. A graisenização fez-se por substituição inicial do feldspato por quartzo e posterior muscovitização. Essa fácies de borda muitas vezes é a mais significativa em termos de volume, perfazendo de $40 \%$ a $60 \%$ de todo o filão de graisen. Identificam-se freqüentemente ao microscópio pequenos cristais de cassiterita, principalmente inseridos nos minerais micáceos.

A zona intermediária é caracteristicamente uma massa de micas, por vezes com pouco ou nenhum quartzo. São normalmente quartzo-mica graisens de cor esverdeada, acinzentada ou prateada, constituídos por uma trama de geminados de cristais de micas eqüigranulares, de granulação média a grossa. Em alguns casos, foi confirmada a ocorrência de zinwaldita através de microssonda. São comuns cristais de cassiterita inclusos em grãos de quartzo ou inseridos na malha dos minerais micáceos detectáveis por micropetrografia. São comuns também box-works de onde foram lixiviados sulfetos. O contato dessa zona intermediária com a zona de borda é relativamente brusco, marcado por uma diminuição acentuada no teor de minerais micáceos. Normalmente toda a zona intermediária perfaz cerca de $20 \%$ a $30 \%$ de todo o filão de graisen.

A zona de núcleo é caracterizada por um emaranhado de macrocristais de quartzo e micas grossas. Normalmente o quartzo sobrepuja as micas em volume. As micas são normalmente muscovitas prateadas em geminados cristalinos de ate $2,5 \mathrm{~cm}$, com cavidades de dissolução. Foram observados cristais de cassiterita, sobretudo associados ao quartzo. Essa zona perfaz cerca de $10 \%$ a $20 \%$ de todo o filão e, por vezes, é pouco desenvolvida ou até ausente.

Os resultados disponíveis de análises químicas dos "graisens derivados de albita-granitos" estão resumidos na tabela 1. Esses resultados permitem concluir que:

- Os teores de Li e F (até 1.608 ppm e 1,5\%, respectivamente) são proporcionais às quantidades de micas, devendo essas substâncias se relacionarem à rede cristalina desses minerais (zinwaldita e/ou muscovitas flúor-litiníferas).

- Há concentração acentuada de $\mathrm{Sn}$, Mo e Ta nas zonas de núcleo e intermediárias dos filões (teores de até 3.850, $1.160 \mathrm{e}$ $360 \mathrm{ppm}$, respectivamente).

- O Nb e o W são enriquecidos nas zonas mais silicosas, tanto na borda como na zona de núcleo (zona de borda com até 194 e 480 ppm; zona de núcleo com até 128 e 1.200 ppm, respectivamente).

- Bi é bastante enriquecido na zona intermediária micácea (até $5.800 \mathrm{ppm})$.

- Os maiores teores obtidos pela moagem de amostras roladas em drenagens e posterior concentração por bateamento e análise a lupa foram da ordem de $2,5 \mathrm{~kg} / \mathrm{t}$ de cassiterita e até mais de $50,0 \mathrm{~kg} / \mathrm{t}$ de wolframita, e teores menos significativos de tantalina-columbita.

Quanto à origem, acredita-se que as mineralizações nesses graisens sejam oriundas de um fluido mineralizante primário, com aporte suplementar de produtos remobilizados dos albita-granitos. 


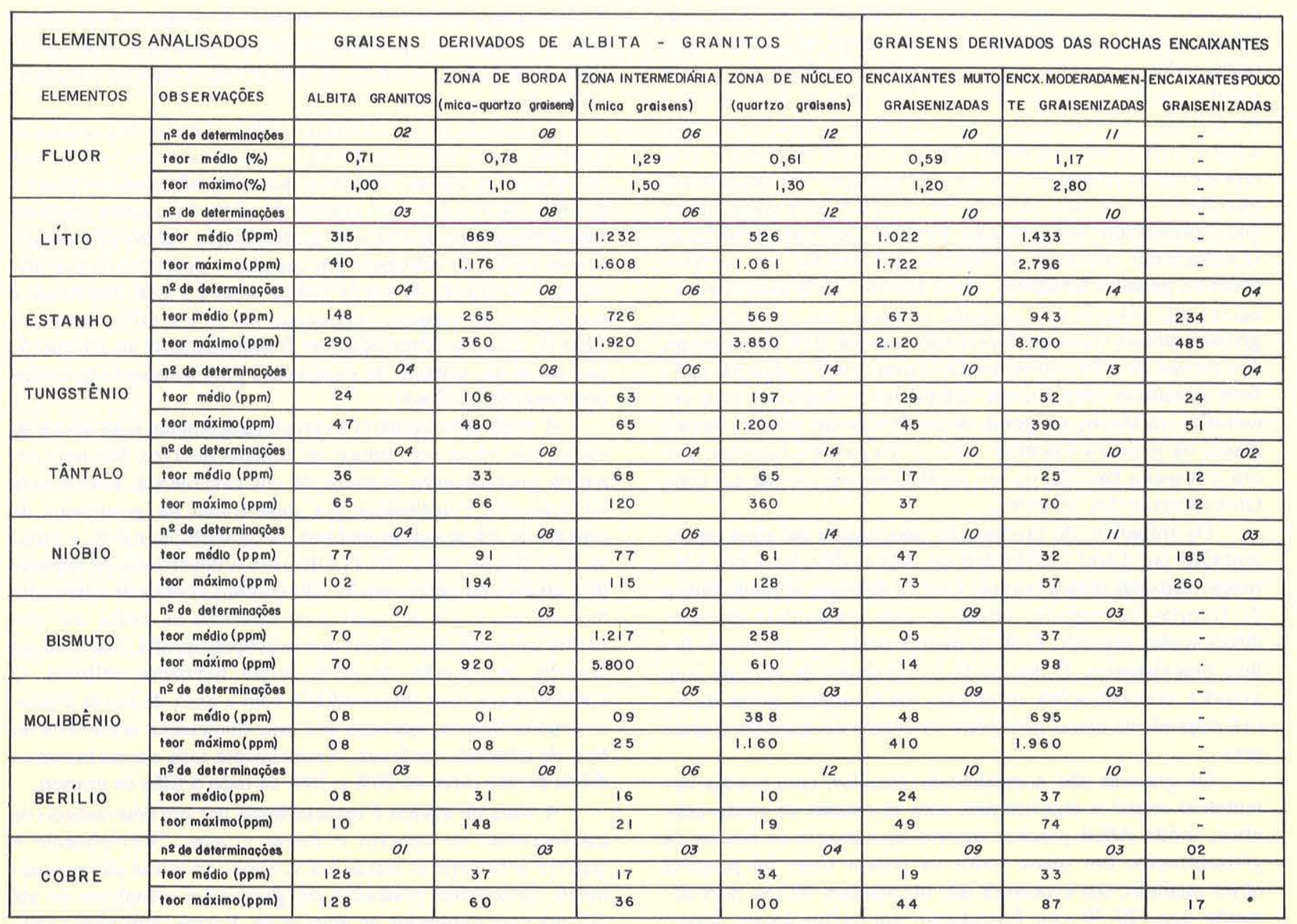

Tabela 1 - Sintese dos resultados analíticos

A ocorrência de área geoquimicamente anômala, com cerca de $1 \mathrm{~km}$ de comprimento e $300 \mathrm{~m}$ de largura, onde incidem as melhores ocorrências minerais, faz com que se considere como boas as perspectivas da ocorrência de minérios primários de interesse.

Graisens derivados das rochas encaixantes No Alvo "Cantagalo" ocorre uma suíte de graisens desenvolvidos sobre as rochas locais. Diferencia-se daquela antes descrita por não se associarem diretamente a massas ígneas. São exograisens formados por substituição e enriquecimento de xistos e gnaisses em $\mathrm{Si}$ e K, em graus variados.

Como se verá, a mineralogia das rochas, os minerais de minério e a área de ocorrência permitem individualizar claramente esse grupo.

Ocorrências dispersas desse tipo são identificadas em uma faixa de cerca de $5 \mathrm{~km}$, com largura variável de 200 até $800 \mathrm{~m}$, totalizando cerca de $2 \mathrm{~km}^{2}$ de área. A faixa é alongada, de maneira quase concordante com as unidades litologicas, ocorrendo exclusivamente a SE da faixa de leucognaisses (Fig. 5).

Pouco se sabe, no detalhe, da associação e das proporções de substituição dessas rochas graisenizadas em relação às encaixantes preservadas. Supõe-se, da descrição de blocos rolados, que em certos setores da faixa ocorram corpos relati- vamente isolados, esporádicos e, em outros setores, os filões sejam concentrados e tenham-se aí grandes massas graisenizadas.

A maior parte das informações são obtidas de blocos de drenagens. Aparentemente, são filões desenvolvidos paralelamente entre si, compondo feixes com direção E-W. Esses filões, quando bem desenvolvidos, constituem-se de um núcleo de quartzo branco, leitoso, envolvido por micas desenvolvidas aleatoriamente. As encaixantes próximas (gnaisses ou micaxistos) por vezes mantêm aspectos estruturais originais, mas com sua mineralogia modificada; isto é marcado pelo desenvolvimento acentuado de micas. No geral, a graisenização é melhor identificável com estudos micropetrográficos.

$\mathrm{Em}$ algumas regiões nas quais os processos foram mais intensos, há venulações de quartzo tabulares, de espessuras da ordem de $1 \mathrm{~cm}$, espaçadas poucos centímetros entre si. Nesses locais, as rochas originais foram intensamente graisenizadas e aí ocorrem as maiores anomalias geoquímicas de $\mathrm{Sn}$, detectadas em sedimentos de drenagens e solos.

Sem dúvida, os controladores dessas ocorrências são as propriedades físico-químicas das encaixantes, assim como as fraturas que permitiram o acesso das soluções mineralizadoras. Por motivos ainda não elucidados, a faixa mais meridional de micaxistos a biotita é a mais favorável. 
Macroscopicamente, por comparação, as amostras podem ser facilmente classificadas como "encaixantes muito graisenizadas", "encaixantes moderadamente graisenizadas" ou ainda "encaixantes pouco graisenizadas". Esses padrōes foram de certa forma confirmados pelas assembleias mineralogicas descritas ao miscroscópio. O que mais diferencia esses tipos é a preservação da estrutura das rochas encaixantes, já que a textura é mais facilmente modificada. Uma ilustração esquemática da forma de ocorrência desses tipos é apresentada na figura 8.

Com exceção das rochas muito graisenizadas, ๔ possível identificar facilmente o tipo litol6gico original, como micaxistos, gnaisses finos, augengnaisses, rochas pegmatoides etc.

O grupo das "encaixantes muito graisenizadas" compreende verdadeiros graisens heterogêneos, com granulação diferenciada das micas, mas sempre constituindo massas em que os cristais se dispõem aleatoriamente. As rochas compõem-se basicamente de micas e quartzo. Os minerais micáceos são normalmente os constituintes principais, tendo sido descritas micas brancas, zinwaldita e muscovita. O quartzo normalmente é o segundo maior constituinte mineralógico, esporadicamente o primeiro ou ainda $\varepsilon$ ausente. Em somente dois pontos foram descritos cristais de albita; esse mineral preservou-se da graisenização quando incluso em quartzo. Também raramente são encontrados cristais de topázio ou ainda de feldspato potássico. Opacos são comuns, destacando-se a cassiterita.

O grupo das "encaixantes moderadamente graisenizadas" compreende rochas com estruturas preservadas. Sua mineralogia apresenta normalmente uma dualidade mineralogica em que minerais novos estão coexistindo com a mineralogia antiga em fase de transformação. Os principais constituintes são micas neoformadas e quartzo. A biotita pode ser constituinte de importância; mais raramente, ocorrem o feldspato potássico e plagioclásio. São caracteríticos nessas rochas fenômenos de muscovitização de biotitas. A cassiterita ê um dos principais minerais opacos perfazendo, em casos especiais, teores de ate $5 \%$ da rocha, avaliados em lâmina delgada.

O grupo das "encaixantes pouco graisenizadas" compreende rochas com todos os aspectos macroscópicos das rochas encaixantes originais. Mostram ao microscópio mineralizações de micas, a preservação do plagioclásio e a ocorrência de cassiterita.

Em 18 das 25 rochas estudadas por micropetrografia, foram detectados cristais de cassiterita. Em 13 delas a cassiterita ocorre como pequenos grânulos ou acículas inclusas nos minerais micáceos e em cinco amostras como cristais disseminados na rocha, por vezes constituindo agregados.

Esporadicamente, são encontrados tipos silicosos com box-works de sulfetos; em casos especiais, com mineralização de molibdenita.

Cerca de 28 amostras dessa categoria foram encaminhadas para análises químicas com determinaçőes para $\mathrm{F}, \mathrm{Sn}, \mathrm{Nb}$, $\mathrm{Be}, \mathrm{Mo}, \mathrm{Bi}, \mathrm{Cu}, \mathrm{Pb}, \mathrm{Zn}, \mathrm{Li}, \mathrm{W}, \mathrm{Ta}$ e os resultados obtidos estão sintetizados na figura 7.

Esses resultados permitem que se conclua que:

- As principais mineralizações estaníferas primárias relacionam-se às rochas muito graisenizadas (teor médio de $\mathrm{Sn}=$ $670 \mathrm{ppm}$ ) e às moderadamente graisenizadas (teor médio de $\mathrm{Sn}=950 \mathrm{ppm})$. Foram obtidos teores analíticos máximos, em ambos os tipos, de $0,87 \%$ de $\mathrm{Sn}$.

- São notáveis os enriquecimentos de F (até 2,8\%) e Li (até $0,28 \%$ ), que devem ser associados à micas neoformadas (zinwaldita).

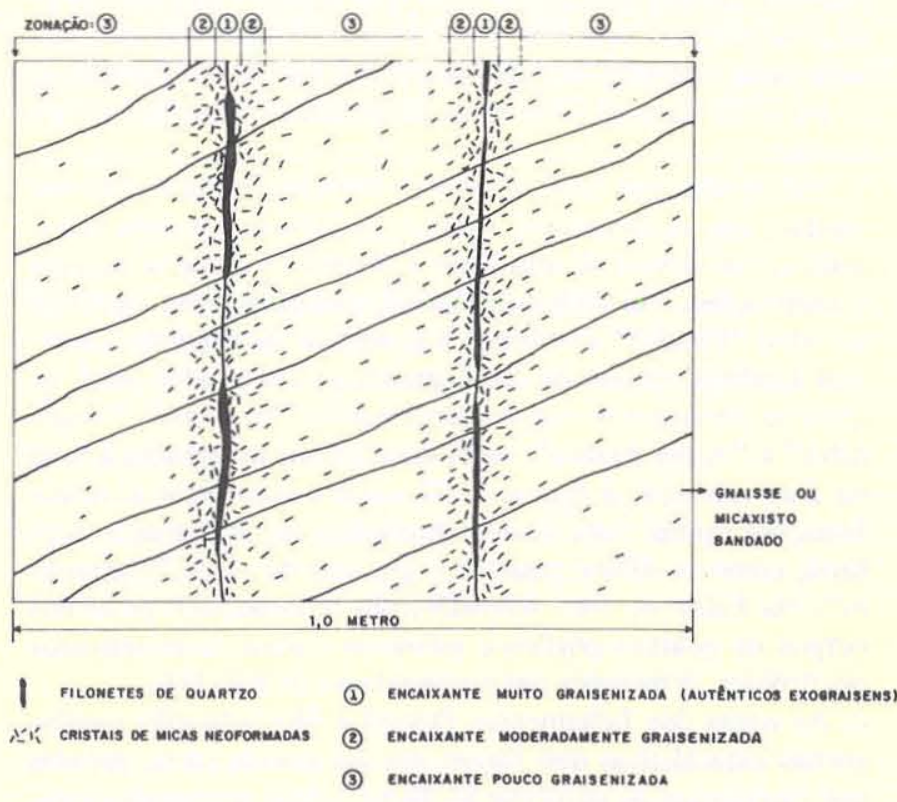

Figura 7 - Ilustração esquemática de filão de "graisen derivado das rochas encaixantes"

- Além do $\mathrm{Sn}$, são também interessantes os teores de Mo, tendo sido obtido atê $0,19 \%$ em rocha silicosa com molibdenita.

- Os teores de $\mathrm{Be}, \mathrm{Bi}, \mathrm{Cu}, \mathrm{Pb}, \mathrm{Zn}$ e Ta såo menos significativos.

Em linhas gerais, os "graisens derivados das rochas encaixantes" sâo mineralizados quase somente a cassiterita, tendo sido localmente evidenciado mineralizaçöes também com woll ramita. Talvez, devido à existência de feixes de fraturas paralelas e próximas entre si, existam grandes áreas com graisenização generalizada. Nas regiões mais potenciais ocorrem venulações preenchidas por quartzo, dispostas de maneira plano-paralela ou em stock-works.

Conforme se viu, tanto os "graisens derivados de albitagranitos", quanto os "graisens derivados de rochas encaixantes" relacionam-se a fraturamentos, de preferência de direção E-W ou em zonas de falhamentos/fraturamentos mais antigos em relação à época de formação dos graisens. Essa direção EW pode corresponder a sistemas de fraturas distencionais sintéticas geradas pela "Falha do Putunã", como se verá adiante. Acredita-se que não só a origem dos filōes mas também o emplacement das massa ígnea geradora de soluções estejam relacionadas a essas fraturas distencionais.

\section{OS FALHAMENTOS DO LESTE DO PARANÁ E SUAS IMPLICAÇÕES METALOGENÉTICAS Os trabalhos} realizados conduziram à idéia da existência de metalogenia especificamente relacionada aos grandes falhamentos transcorrentes que ocorrem nas periferias da área trabalhada. Por isso, dado o volume de informações disponíveis e o próprio relacionamento das mineralizações da área a essas estruturas, resolveu-se relatar alguns aspectos observados e/ou interpretados conforme os itens relacionados a seguir.

a. São reconhecidas três falhas transcorrentes, paralelas entre si, de direção N55-60E, enquadradas pelo esboço geológico da figura 2. A noroeste da área ocorre a Falha da Lancinha 
(também chamada de lineamento Itapeúna ou Falha de Cubatâo); na porção central da área, ocorre o falhamento denominado neste trabalho de Falha do Putunã (ou do Rio Putunã); e, na parte SE da área, uma outra, denominada Falha de São Sebastião.

b. Nas regiōes próximas à Falha do Putunã e Falha de São Sebastião, são reconhecidos indícios de intensa atividade magmática, que devem se relacionar a diversos e distintos eventos e reativações. Na Falha do Putunã, metaperidotitos ocorrem no Alvo "Paraíso" e próximo à localidade de Serrinha. Ocorrem também corpos de álcali-granitos cataclasados entre os quais se destacam os corpos denominados "Serrinha", "Nagib Silva" e "Areia Branca"; estes dois últimos localizados a leste da área referente à figura 2 . Há ainda a considerar as manifestações ígneas mais jovens, destituídas de deformação textural, como os albita-granitos e graisens do Alvo "Cantagalo". Na Falha de São Sebastião, são reconhecidos pequenos corpos de quartzo-pórfiro e inúmeros corpos de metabasitos porfiroides, detectados nas proximidades da BR-116.

c. As zonas dos falhamentos Putunã e São Sebastião contêm rochas cataclásticas que foram, em sua grande parte, geradas por fenômenos de deformação dúctil e mais raramente rúptil. Este fato vem demonstrar que os níveis atuais de exposição correspondem ao de rochas geradas a profundidades consideráveis e que o próprio plano de fah amento não seria local mais favorável a mineralizações. Entretanto, ao que parece, houve reativaçöes talvez mais recentes que, atuando já em ambiente supracrustal, provocaram microfraturamentos cerrados (deformações rúpteis), a exemplo do observado no Alvo "Paraíso"; neste último caso, há condições de ocorrer mineralizações no próprio plano de falha.

d. As zonas dos falhamentos Putunã e São Sebastião demarcam também alinhamentos de ocorrências minerais e anomalias geoquímicas. Na Falha de São Sebastião alinham-se em um setor anomalias polimetálicas nas quais se destacam o $\mathrm{Zne}$ $\mathrm{Pb}$, e foram identificadas ocorrências minerais de pirita e galena. Na Falha do Putunã alinham-se anomalias de Sn (figura 3), F, W, $\mathrm{Nb}$, Ta e também $\mathrm{Cu}, \mathrm{Pb}$ e $\mathrm{Zn}$. Foram detectadas ocorrências minerais de $\mathrm{Sn}, \mathrm{W}, \mathrm{Nb}$ e Ta na área em questão e de $\mathrm{Pb}, \mathrm{Zn}$ e $\mathrm{F}$, mais a leste.

e. As mineralizações podem se localizar diretamente na zona de cisalhamento (Alvo "Paraíso", por exemplo) ou próximas ao mesmo (Alvo "Cantagalo", por exemplo). Essas ocorrências situados fora e próximas da zona de cisalhamento são atribuídas a sistemas de fraturas sintéticas de direção aproximada E-W. Este fato é comprovado no Alvo "Cantagalo" pela incidência de corpos de graisens dispostos em fraturas EW, conforme se evidencia por medidas estruturais e pela disposição de anomalias geoquímicas de solos.
CONCLUSÕES No contexto geológico do Estado do Paraná, houve granitogênese responsável pela formação de graisens mineralizados a $\mathrm{Sn}, \mathrm{W}, \mathrm{Nb}, \mathrm{Ta}, \mathrm{Bi}$ e Mo. Tal granitogênese seria pós-tectônica em relação ao último ciclo orogenético, o que é evidenciado pela ausência de deformações nas rochas a ela relacionada.

As apofises e os pequenos domos graníticos relacionados aos graisens são de álcali-granitos, mas é impossível, por ora, obter conhecimentos petrográficos ou petrológicos de um possível corpo gerador dessas manifestações devido o mesmo não estar aflorante.

Fraturamentos e falhamentos são importantes controladores do emplacement desses granitos e das mineralizaçōes associadas. Em escalas regionais, são importantes os grandes falhamentos transcorrentes e, no detalhe, as zonas de cisalhamento ou de fraturamento; notadamente de direção aproximada E-W, do tipo fraturas sintéticas.

As informações relacionadas à pesquisa mineral são ainda de uma fase inicial de trabalhos, mas já revelando que o Alvo "Cantagalo" é promissor para conter depósitos minerais primários de Sn e W, aos quais podem estar associados a $\mathrm{Ta}, \mathrm{Nb}$, Bi e talvez Mo. Essa consideração é alicerçada por vários fatores, entre os quais se destacam.

1. O grau de concentraçẫo de minerais de interesse, conseguindo-se nas poucas amostras obtidas e estudadas teores de minérios.

2. A tipologia de graisens de fraturas que são rastreados por meio de geoquímica de solos, com anomalias com até $1 \mathrm{~km}$ de extensão e centenas de metros de largura.

3. As possibilidades de ocorrerem chaminés, sobretudo em regiōes de cruzamento de fraturas.

4. As similaridades desse contexto com áreas tradicionalmente produtoras de minérios, clássicas na literatura geológica específica do assunto.

Agradecimentos $\mathrm{O}$ autor externa seu agradecimento a equipe técnica da Mineropar-Minerais do Paraná S.A., em especial ao Dr. João Carlos Biondi, pelo constante apoio à realização das sucessivas etapas que permitiram alcançar os resultados ora explanados, pela valiosa ajuda nas discussões sobre o tema e pela revisão do texto; às geólogas Rosa Maria de Souza e Kátia Norma Siedlecki, pelas contribuições em assuntos relacionados à micropetrografia e petrografia de minerais pesados; ao geólogo Otávio Boni Licht, pelas contribuiçōes em assuntos relacionados a prospeç̧ão geoquímica; e ao ge6́logo Gil Francisco Piekarz, pelo auxílio nos trabalhos de cartografia geológica e ao geólogo Dr. Onildo João Marini, pelo intercâmbio de informaçōes técnicas.

\section{REFERÊNCIAS BIBLIOGRẢFICAS}

BIGARELLA, J.J.; SALAMUNI, R.; PINTO, V.M. 1967. Geologia do Pré-Devoniano e intrusivas subseqüentes da Porção Oriental do Estado do Paraná. Curitiba, Universidade Federal do Paraná. $347 \mathrm{p}$.

FALCADE, D. 1982. Geologia e potencial econômico da área CapivariPardo. Curitiba, Mineropar. 163 p. (Rel. int.)

FRITZSONS Jr., O. 1985. Prospecção de detalhe no alvo $S n-$ Paraíso Fase I. Curitiba. Mineropar. 29 p. (Rel. int.).

FRITZSONS Jr., O. 1986. Prospecção de detalhe no alvo $\mathrm{Sn}-$ Cantagalo; fase I. Curitiba, Mineropar. 51 p. (Rel. int.)

FRITZSONS Jr., O.; BIONDI, J.C.; PIEKARZ, G.F. 1985. Verificação de anomalias geoquímicas nas áreas Capivari-Pardo e Antiforme do Setuva. Curitiba, Mineropar, 4 v. (Rel. int.)

FRITZSONS Jr., O.; PIEKARZ, G.F.; FALCADE, D. 1982. Geologia e potencial econômico do Grupo Setuva, PR. In: CONGR.
BRAS. GEOL., 32, Salvador, 1982. Anais... Salvador, SBG. v. 3, p. $978-1001$.

FUCK, R.A.; MARINI, O.J.; TREIN, E.; MURATORI, A. 1971. Geologia do leste paranaense. In: CONGR. BRAS. GEOL., 25, São Paulo, 1971. Anais... São Paulo, SBG. v. 1, p. 121-130.

LICHT, O.A.B. 1986. Interpretação dos dados de geoquímica de solos - Projeto Estanho - Cantagalo. Curitiba, Mineropar. 14 p. (Rel, int.)

SCHERBA, G.N. 1970. Greisens. Int. Geol. Rev., 12:114-151.

TAYLOR, R.G. 1979. Geology of tin deposits. Amsterdam, Elsevier. $534 \mathrm{p}$.

MANUSCRITO 405 Recebido em 24 de novembro de 1986 Revisão aceita em 10 de fevereiro de 1988 